\title{
Serological assay for anti-SARS-CoV-2 antibodies improves sensitivity of diagnosis of COVID-19 patients
}

\author{
Davood Rostamzadeh ${ }^{1}$ - Sahar Mortezagholi ${ }^{2} \cdot$ Maedeh Alinejad $^{3}$. Seyed Reza Jooya ${ }^{3} \cdot$ Maryam Eskandarian $^{3}$.

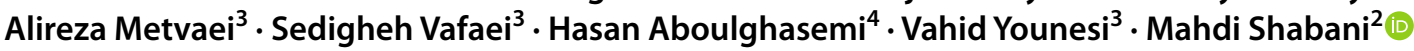

Received: 7 January 2021 / Accepted: 11 September 2021 / Published online: 25 September 2021

(c) The Author(s), under exclusive licence to Springer-Verlag GmbH Germany, part of Springer Nature 2021

\begin{abstract}
The emergence of SARS-CoV-2, responsible for coronavirus disease-2019 (COVID-19), has become a major global health problem. The molecular testing is the accepted assay in SARS-CoV-2 detection. However, there are several reasons for low sensitivity by RNA detection, causing challenges in SARS-CoV-2 diagnosis. In this study, we aimed to investigate serological patterns of SARS-CoV-2 specific IgM, and IgG in 111 hospitalized, and 34 recovered COVID-19 patients and 311 prepandemic normal serum specimens by ELISA. The validity of the ELISA kits was evaluated using samples from normal and recovered cases. This showed that $98.1 \%$, and $98.4 \%$ of prepandemic normal samples were negative for anti-SARS-CoV-2 $\mathrm{IgM}$, and IgG, respectively. Assessment of 34 COVID-19 confirmed recovered patients showed a test sensitivity of 76.5\%, and $94.1 \%$ for IgM, and IgG, respectively. In COVID-19 hospitalized patients, $42.3 \%$, and $51.4 \%$ were positive for IgM and $\mathrm{IgG}$, respectively. Viral RNA was not detectable in $43.3 \%$ of the hospitalized patients. Interestingly, combined molecular and serological testing improved the sensitivity of COVID-19 diagnosis to $79.6 \%$. Using PCR with combined IgM/IgG results augmented the patient diagnosis sensitivity to $65.3 \%$ and $87.2 \%$ in $\leq 7$ days, and $>7$ days intervals, respectively. Overall, serological tests in combination with PCR can improve the sensitivity of COVID-19 diagnosis.
\end{abstract}

Keywords SARS-CoV-2 $\cdot$ COVID-19 $\cdot$ Diagnosis $\cdot$ Antibody $\cdot$ Serology $\cdot$ ELISA $\cdot$ PCR

\section{Introduction}

A cluster of patients with "unknown viral pneumonia" was reported, in Wuhan, Hubei province, China in late December 2019 [1, 2]. Later on, WHO officially announced the disease as coronavirus disease 2019 (COVID-19), and the causative virus was called SARS-CoV-2 [3]. SARS-CoV-2 infection has quickly spread across China and worldwide [4,

Edited by Stipan Jonjic.

Mahdi Shabani

msshabani@sbmu.ac.ir

1 Medicinal Plants Research Center, Yasuj University of Medical Sciences, Yasuj, Iran

2 Department of Immunology, School of Medicine, Shahid Beheshti University of Medical Sciences, Tehran, Iran

3 Synapse IVD Accelerator, Tehran, Iran

4 Applied Microbiology Research Center, Systems Biology and Poisonings Institute, Baqiyatallah University of Medical Sciences, Tehran, Iran
5]. The most common clinical manifestations of COVID-19 included fever, followed by cough, fatigue, sputum production, shortness of breath, sore throat, headache, diarrhea, and vomiting [1, 6]. In addition, most severe patients exhibited lung CT abnormality such as subsegmental areas of consolidation and multiple ground-glass opacity and infiltration shadows in both lungs $[1,6]$. The most common lab findings in COVID-19 include leukopenia, lymphocytopenia, neutrophilia, high C-reactive protein, and elevated serum alanine and aspartate aminotransferase levels as well as D-dimers $[1,7,8]$. Currently, detection of viral RNA by polymerase chain reaction (PCR)-based technique is the golden lab test and is almost the only way to confirm the clinical diagnosis of COVID-19. However, detection of viral RNA is mostly dependent on the presence of the viral genome in sufficient amounts at the site of sample collection, and RT-PCR assay is incapable of detecting the SARS-CoV-2 in the early stages of infection, and false-negative RT-PCR test results have been reported in subjects for up to 2 weeks from symptoms onset $[9,10]$. Furthermore, detection of viral RNA from throat or nasopharyngeal swab is mostly associated with 
considerable risk of false-negative results [11]. This can be due to various viral loads in different stages of the infection, improper clinical sampling and nucleic acid extraction, variations in the sensitivity of assays from various manufacturers, insufficient cellular material in the collected samples, and finally lower viral load in upper respiratory tract. These suggest that RT-PCR may not be the best and sole choice for detection of SARS-CoV-2 infection.

Hence, development of more efficient screening methods which are able to detect lower viral loads in the early stages of the disease can be invaluable to ensure timely diagnosis of the patients. Although molecular diagnostic methods for COVID-19 were rapidly developed, multiple serologic assays were developed recently due to a lack of sufficient immunological information about the SARS-CoV-2 virus. Nevertheless, recent limited studies suggested that serological tests might be able to detect those patients with either current or previous infection and a negative PCR test [9, 12]. The serological assay is also very important for fast screening, surveillance, epidemiological studies, and control of the current COVID-19. In the present study, we aimed to investigate the specific serologic response to SARS-CoV-2 in 111 hospitalized and 34 recovered COVID-19 patients using enzyme-linked immunosorbent assay (ELISA), as controlled by 311 prepandemic normal serum specimens.

\section{Materials and methods}

\section{Patients and samples}

During 20 January to 14 April 2020, a total of 111 hospitalized COVID-19 patients admitted in Dr. Shariati hospital and 34 recovered COVID-19 patients recruited to Baqiyatallah hospital included in the present study. The diagnosis of COVID-19 was based on the clinical manifestations, including common symptoms and signs, chest CT scan, laboratory findings, as well as primer-probe-based real-time RT-PCR. The recovered patients were selected from confirmed COVID-19 cases who were recovered and negative for SARS-CoV-2 RT-PCR and 14 days passed their recovery. For all enrolled patients, demographic information (age, sex, coexisting disorders), clinical findings and their timing, chest CT scan, and real-time RT-PCR results were obtained from clinical records. All patients had mild to severe acute respiratory syndromes and/or abnormalities in chest CT images. In addition, 311 prepandemic normal serum samples collected 2 years before COVID-19 pandemic and stored at $-70{ }^{\circ} \mathrm{C}$ in the biobank of digestive diseases research institute, Tehran-Iran, were used for validation of serologic tests. Written informed consent was obtained from each enrolled patient. The patients' sera were immediately stored at $-20^{\circ} \mathrm{C}$. Nasopharyngeal and oropharyngeal samples from respiratory tracts were used for SARS-CoV-2 RNA detection by quantitative RT-PCR. In case of negative results, RT-PCR was repeated using new samples. The PCR results were extracted from the clinical records of each patient. This study was reviewed and approved by the Medical Ethical Committees of Shahid Beheshti University of Medical Sciences (approval number IR.SBMU.MSP.REC.1399.031).

\section{RNA extraction and RT-PCR assay}

Total RNAs were extracted from patients' nasopharyngeal and oropharyngeal swabs using column-based kit as instructed by manufacturer (BEHGENE, cat. number: BPVD050 Fars, Iran). Target genes of SARS-CoV-2 were detected using approved primer-probe-based Real-time PCR (Pishtaz Teb Diagnostics, cat. number: PT-COVID.19-100 Tehran, Iran). RT-PCR assay was performed under the following conditions: incubation at $50^{\circ} \mathrm{C}$ for $20 \mathrm{~min}$ and $95^{\circ} \mathrm{C}$ for $3 \mathrm{~min}$, followed by 45 cycles of denaturation at $94{ }^{\circ} \mathrm{C}$ for $10 \mathrm{~s}$, then annealing, extending and collecting fluorescence signal at $55^{\circ} \mathrm{C}$ for $40 \mathrm{~s}$. The fluorescence signal of HEX, FAM and ROX were detected for $\mathrm{N}$ gene and RdRP region of SARS-CoV-2 and RNase P as internal control, respectively using Rotor-Gene Q MDx 5plex HRM (Qiagen, Germany). If a typical S-type amplification curve is detected by the FAM or HEX channel, with $\mathrm{Ct} \leq 40$, it indicates that SARS-COV-2 virus is positive.

\section{Antibody measurement using enzyme-linked immunosorbent assay (ELISA)}

IgM, and IgG antibodies specific to SARS-CoV-2 nucleocapsid antigen were detected in serum samples using corresponding ELISA kits (Pishtaz Teb Diagnostics, Tehran, Iran; cat. numbers: PT-CoV2 IgM-96, and PT-CoV2 IgG96) according to manufacturer's instructions. In summary, the serum samples were diluted 1:100 in sample diluent and then $100 \mu \mathrm{l}$ of each positive and negative control sera and 1:100 diluted serum specimens were added into appropriate wells in duplicate. After 30 min incubation at $37^{\circ} \mathrm{C}$, the well contents were flicked and washed 5 times using working wash buffer. Next, $100 \mu \mathrm{l}$ of appropriate conjugates (antihuman IgM-HRP, or anti-human IgG-HRP) were applied into the wells and incubated for $30 \mathrm{~min}$ at $37^{\circ} \mathrm{C}$. After washing the wells for 5 times, $100 \mu \mathrm{l}$ of chromogenic substrate was dispensed into the wells. All plates were incubated at room temperature and darkness for $15 \mathrm{~min}$ in order for the color to develop. The reaction was then stopped by adding $100 \mu \mathrm{l}$ stop solution, and the optical densities of the wells were measured at $450 \mathrm{~nm}$ as well as $630 \mathrm{~nm}$ as the reference filter using ELISA reader (BioTek Instrument Inc., Winooski, VT, USA). Both negative and positive controls were included in all assays. Those samples with OD450 nm/ 
OD630 nm above the cut-off value of 1.1 were considered to be positive. The cut-off value was calculated based on mean \pm 3 SD of prepandemic normal serum samples collected before COVID-19 pandemic.

\section{Statistical analysis}

The findings were analyzed using SPSS 22.0 software (SPSS Inc., Chicago, IL, USA) and GraphPad Prism software version 8.0 (GraphPad Software, Inc., San Diego, USA). Continuous variables were displayed as mean \pm standard deviation (mean $\pm \mathrm{SD}$ ) and categorical variables were reported as counts and percentages. All groups were tested for normal distribution using the Shapiro-Wilk test. Mann-Whitney $U$ test was used for non-parametric comparisons.

Test values were calculated as sample ODs divided by cut-off index as instructed by the manufacturer. Those test values above 1.1 and below 0.9 were considered to be positive and negative, respectively, while those values between 0.9 and 1.1 considered to be borderline. A $p$ value less than 0.05 was considered to be statistically significant. Asterisks $*, * *$, and $* * *$ were used to show those $p$ values between $0.01-0.05,0.001-0.01$, and $0.0001-0.001$, respectively.

\section{Results}

\section{SARS-CoV-2 RT-PCR and chest CT findings in COVID-19 patients}

A total of 111 hospitalized COVID-19 patients were enrolled in this study. The inclusion criteria were determined for hospitalized patients based on clinical symptoms and signs and diagnostic chest CT scan. The mean age of the hospitalized COVID-19 patients was 56 years (inter-quartile range 31-90 years; range 16-90 years) and $57.7 \%$ were males (Table 1). The most common symptoms of COVID-19 cases included fever (20.7\%), weakness (14.5\%), dry cough (20.7\%), dyspnea (31.7\%), and myalgia (6.9\%).

COVID-19-related chest CT patterns were observed in 99.1\% (109/110) of hospitalized patients. The main CT findings in COVID-19 hospitalized patients were groundglass opacity (89.6\%), bilateral patchy shadows (24.6\%), and consolidation (35.1\%) (Table 1). Interestingly, some CT findings appeared to be more frequent in patients over 50 as compared to those under 50 years old, including: patchy infiltrates (30.8\% vs. $12.5 \%)$, and consolidation ( $44.4 \%$ vs. $37.5 \%)$. In hospitalized patients, SARS-CoV-2 RNAs were detected in the upper respiratory tract of $56.7 \%$ (51/90) patients using real-time RT-PCR as stated in the medical
Table 1 Demographic and clinical characteristics of 111 enrolled patients

\begin{tabular}{ll}
\hline Characteristic & Results \\
\hline Age (years) & \\
Age, mean \pm SD & $56.97 \pm 17.13$, range of 31-90 \\
Age $\leq 50$ & $25(79.41 \%)$ (available data) \\
Age $>50$ & $53(20.59 \%)$ (available data) \\
Male & $64(57.7 \%)$ \\
Female & $47(42.3 \%)$ \\
Results of RT-PCR assay & \\
Positive & $56.7 \%(51 / 90)$ \\
Negative & $43.3 \%(39 / 90)$ \\
CT scan results and findings & \\
Positive & $99.1 \%(109 / 110)$ \\
Negative & $0.9 \%(1 / 110)$ \\
Ground-glass opacity & $89.6 \%(69 / 77)$ \\
Patchy infiltrate & $24.6 \%(19 / 77)$ \\
Consolidation & $35.1 \%(27 / 77)$ \\
\hline
\end{tabular}

Table 2 Serological detection of anti-SARS-CoV-2 antibodies in 34 recovered COVID-19 patients

\begin{tabular}{ll}
\hline Antibodies & Positive percentage $(N)$ \\
\hline IgM/IgG & $94.1 \%(32 / 34)$ \\
IgG & $94.1 \%(32 / 34)$ \\
IgM & $76.5 \%(26 / 34)$ \\
\hline
\end{tabular}

records of patients. One patient with normal CT showed positive RT-PCR for SARS-CoV-2.

\section{Profile of SARS-CoV-2 antibodies in normal and recovered COVID-19 subjects}

Serum specimens from normal subjects were tested using IgM, and IgG SARS-CoV-2 ELISA kits to evaluate assay's specificity. This showed a test's specificity of $98.1 \%$ (304 negative out of 311), and 98.4\% (306 negative out of 311) for IgM, and IgG antibodies, respectively. On the other hand, blood samples of the recovered patients were obtained 14 days after recovery and tested for assay's sensitivity. In 34 COVID-19 recovered patients, assay's sensitivity was found to be $76.5 \%$ (26/34), and 94.1\% (32/34) for IgM, and IgG, respectively (Table 2). Combined use of SARS-CoV-2 IgM/IgG did not increase the assay's sensitivity (94.1\%) compared to SARS-CoV-2 IgG (Table 2). In other words, $94.1 \%$ of recovered patients showed at least one SARS-CoV-2 specific antibody from IgM, or IgG isotypes. The presence of specific IgM after 14 days of recovery in most patients could be interesting as it is expected to be produced during acute phase of infections but still persisting at recovery phase. 
Table 3 Viral RNA and antibody results in 111 hospitalized COVID-19 patients

\begin{tabular}{ll}
\hline Test & Positive \\
\hline PCR & $56.7 \%(51 / 90)$ \\
$\operatorname{IgM}$ & $42.3 \%(47 / 111)$ \\
$\operatorname{IgG}$ & $51.4 \%(57 / 111)$ \\
IgM/IgG & $55.9 \%(62 / 111)$ \\
PCR/IgM/IgG & $79.6 \%(86 / 108)$ \\
\hline
\end{tabular}

Table 4 Viral RNA and antibody results in the hospitalized COVID19 patients detected by RT-PCR and ELISA in different days from initial onset of symptoms

\begin{tabular}{lll}
\hline Test & $\leq 7$ days & $>7$ days \\
\hline PCR positive & $57.5 \%(42 / 73)$ & $46.7 \%(7 / 15)$ \\
IgM/IgG & $34.0 \%(17 / 50)$ & $69.2 \%(27 / 39)$ \\
PCR/IgM/IgG & $65.3 \%(32 / 49)$ & $87.2 \%(34 / 39)$ \\
IgM & $28.0 \%(14 / 50)$ & $51.3 \%(20 / 39)$ \\
IgG & $34.0 \%(17 / 50)$ & $61.5 \%(24 / 39)$ \\
\hline
\end{tabular}

\section{Profile of SARS-CoV-2 antibodies in hospitalized COVID-19 patients}

We assessed patients' antibody profiles to see whether serologic testing could help to identify patients with COVID-19. Among COVID-19 hospitalized patients, 42.3\% (47/111), and $51.4 \%(57 / 111)$ were found to be positive for antiSARS-CoV-2 IgM, and IgG, respectively (Table 3). Combined use of SARS-CoV-2 IgM/IgG increased the test's sensitivity for hospitalized COVID-19 patients to 55.9\% (62/111) (Table 3). There was a positive correlation between test values of $\operatorname{IgM}$ and $\operatorname{IgG}(r=0.82, P<0.001)$.
Furthermore, the sampling time was subdivided into two periods encompassing $\leq 7$ days, and $>7$ days (8-18 days) after the onset of symptoms, then, the seropositivity rate for each of $\operatorname{IgM}$, and $\mathrm{IgG}$ antibodies as well as their combinations were analyzed in defined intervals. The test's sensitivity was found to be increasing by passing time of symptoms onset, so that the sensitivity of $\operatorname{IgM}$, and $\mathrm{IgG}$ assays were $28.0 \%$ (14/50), and $34.0 \%$ (17/50), respectively, in time period of $\leq 7$ days (Table 4 and Fig. 1) and it increased to 51.3\% (20/39), and 61.5 (24/39) in time period of $>7$ days, respectively (Table 4). These results showed that the combination of SARS-CoV-2 IgM, and IgG could improve the test's sensitivity at time period of $>7$ days but not at the early stages of disease ( $\leq 7$ days).

The mean of sample to cut-off value of SARS-CoV-2 IgM in recovered patients (mean \pm SD: $4.47 \pm 4.46$ ) was significantly higher than hospitalized COVID-19 patients (mean \pm SD: $3.09 \pm 4.70)(P=0.02)$ (Fig. 2). The level of $\mathrm{IgG}$ in the recovered patients $(11.63 \pm 5.94)$ appeared to be higher than hospitalized patients $(9.5 \pm 10.56)$, although no significant difference was seen $(P=0.14)$ (Fig. 2). Our findings showed $\operatorname{IgM}(P=0.02)$ as well as $\operatorname{IgM} / \operatorname{IgG}$ $(P=0.02)$ significantly associated with patchy infiltration frequency in hospitalized COVID-19 patients. In this regard, patchy infiltration were found in $39.3 \%$, and $36.1 \%$, of patients with $\operatorname{IgM}+$, and $\operatorname{IgM} / \mathrm{IgG}+$ as well as $16.3 \%$ and $14.6 \%$, IgM-, and IgM/IgG-patients, respectively. In addition, $83.7 \%$ and $85.4 \%$ of $\operatorname{IgM}$ and $\mathrm{IgM} / \mathrm{IgG}$ negative cases did not have patchy infiltration. Indicating the possible role of antibody mediate immune responses in COVID-19 pathogenesis.
Fig. 1 Levels of SARS-CoV-2 specific IgM, and IgG antibodies in different intervals after symptoms onset in hospitalized COVID-19 patients. The scatter dot plots indicate cut-off values of IgM and IgG specific to SARS-CoV-2 of each sample. The sampling time was subdivided into two periods encompassing $\leq 7$ days, and $>7$ days (8-18 days) after the onset of symptoms, then, the seropositivity rate for each of $\mathrm{IgM}$, and $\mathrm{IgG}$ antibodies was analyzed in defined intervals. The horizontal line defines cut-off value to separate $\operatorname{IgM}$ and $\operatorname{IgG}$ positive and negative samples

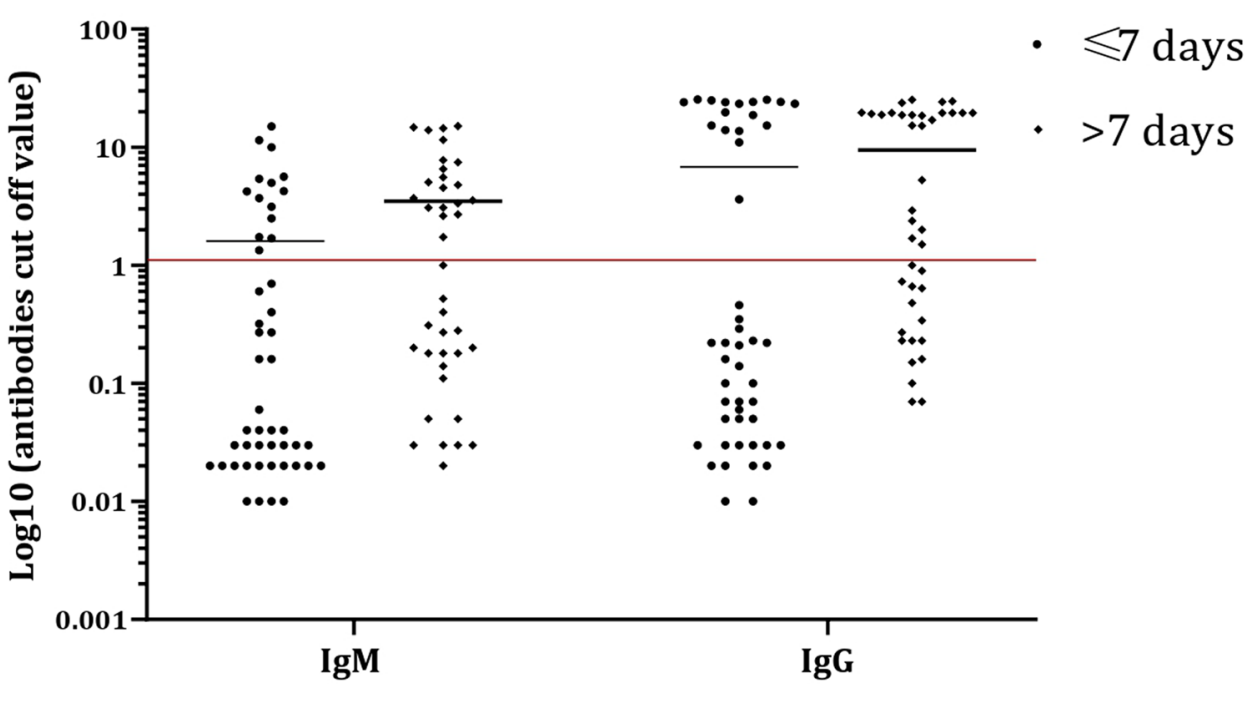

SARS-CoV-2 specific antibody isotypes 


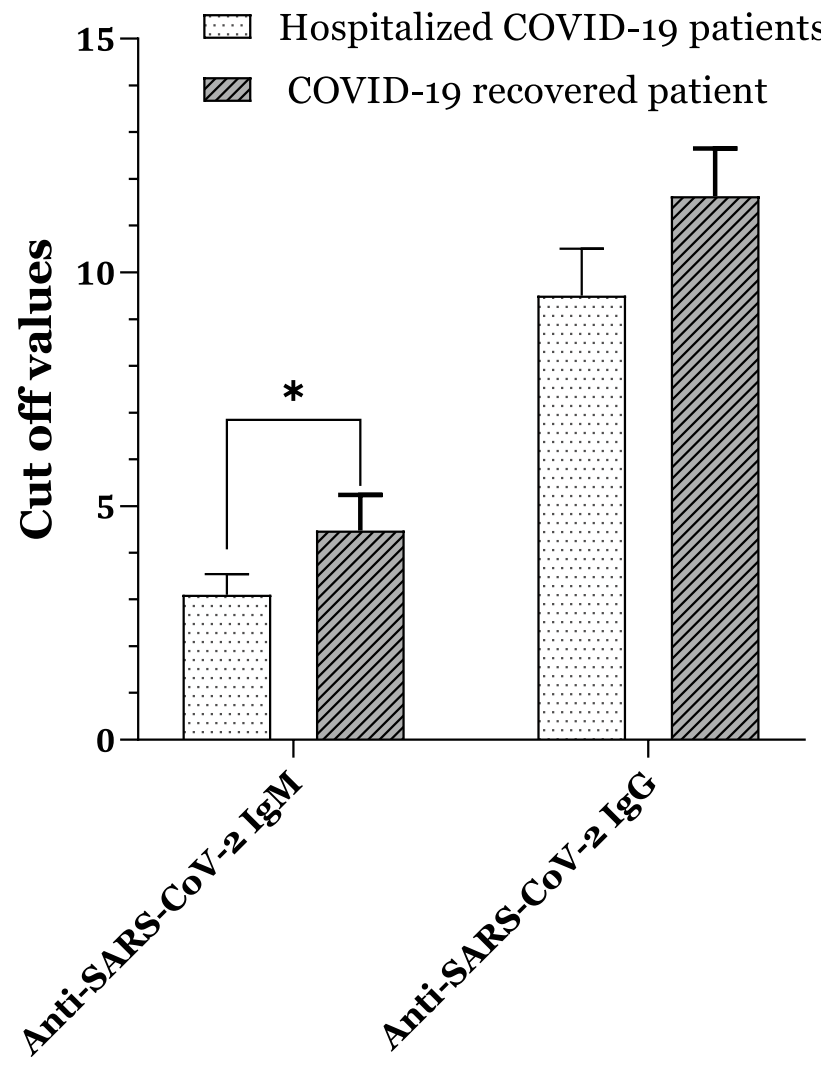

Fig. 2 Comparison of SARS-CoV-2 specific IgM, and IgG antibodies in hospitalized and recovered COVID-19 patients. Cut off values were calculated as sample ODs divided by cut-off index as instructed by the manufacturer. Means of cut-off value in each group for IgM and IgG specific to SARS-CoV-2 have been shown in the graph

\section{Correlation between $\mathrm{CT}$ findings and RT-PCR results with antibody profile}

Detection of viral RNA is almost the golden method to confirm the infection of SARS-CoV-2 in practice. As stated above, the RT-PCR was positive in $56.7 \%$ of hospitalized COVID-19 patients. Checking the rate of positive RNA detection testing in symptoms onset to swabbing time intervals revealed that $57.5 \%$ and $46.7 \%$ of cases were positive for SARS-CoV-2 RT-PCR $\leq 7$ days, and $>7$ days, intervals (Table 4). Importantly, we found that $39 / 90$ (43.3\%) of hospitalized patients had negative RT-PCR (Table 3). In this context, the frequency of patients with anti-SARS-CoV-2 antibodies were evaluated in the RT-PCR negative cases. Our findings indicated that in RT-PCR negative cases, antiSARS-CoV-2 IgM, and IgG were detected in 35.9\% (14/39), and $41 \%$ (16/39) of patients, respectively (Table 5). The antiSARS-CoV-2 IgM, and IgG were also detectable in the two defined intervals between symptoms onset and sampling time, even in the early stage of diseases which expected the PCR has the highest sensitivity for COVID-19 diagnosis (Table 6). Thus, serological assays for combination of
Table 5 Serological detection of anti-SARS-CoV-2 specific antibodies in hospitalized patients with undetectable viral RNA

\begin{tabular}{ll}
\hline Antibodies & Positive \\
\hline $\operatorname{IgM} / \operatorname{IgG}$ & $43.6 \%(17 / 39)$ \\
$\operatorname{IgM}$ & $35.9 \%(14 / 39)$ \\
$\operatorname{IgG}$ & $41 \%(16 / 39)$ \\
\hline
\end{tabular}

$\mathrm{IgM}$, and $\operatorname{IgG}$ resulted in detection of $38.7 \%$, and $62.5 \%$ of RT-PCR negative cases in $\leq 7$ days, and $>7$ days intervals between sampling time and symptoms onset, respectively (Table 6). Interestingly, combination of molecular and serological testing greatly improved the sensitivity of COVID19 patient diagnosis. In this regard, when the PCR results were used along with SARS-CoV-2 IgM/IgG in hospitalized patients, the sensitivity increased to $79.6 \%(86 / 108)$ (Table 3). Implication of PCR altogether with one of IgM or $\mathrm{IgG}$ results augmented the patient diagnosis sensitivity to $65.3 \%$ and $87.2 \%$ in $\leq 7$ days, and $>7$ days intervals, respectively (Table 4).

\section{Discussion}

Detection of SARS-CoV-2 RNA by qPCR depends on the presence of a sufficient amount of viral load in tissues. Of note, this method is effective during a short period especially acute phase of infection. While molecular diagnostic methods for COVID-19 have been rapidly developed, several reasons lead to the low sensitivity of this method, which poses a challenge to diagnosis of SARS-CoV-2 infection. This shortcoming of molecular testing was also observed in the current study in which viral RNA was not detectable in 39 out of 90 (43.3\%) of hospitalized patients. On the other hand, there are few reports indicating the importance of serological assays in improving the RT-PCR clinical sensitivity when applied together $[13,14]$. In line with the applicability of serological methods, our results showed that in COVID-19 hospitalized patients $42.3 \%$, and $51.4 \%$ were positive for anti-SARS-CoV-2 IgM, and IgG, respectively. A combination of SARS-CoV-2 IgM/IgG enhances the detection sensitivity of hospitalized COVID-19 patients' detection rate to $55.9 \%$ that is to some extent similar to PCR sensitivity $(56.7 \%)$ in the current study. It is recommended

Table 6 Serological detection of anti-SARS-CoV-2 specific antibodies in 38 hospitalized patients with undetectable viral RNA at different time since onset of symptoms

\begin{tabular}{lll}
\hline Test & $\leq 7$ days & $>7$ days \\
\hline $\operatorname{IgM} / \operatorname{IgG}$ & $38.7 \%(12 / 31)$ & $62.5 \%(5 / 8)$ \\
$\operatorname{IgM}$ & $35.5 \%(11 / 31)$ & $37.5 \%(3 / 8)$ \\
$\operatorname{IgG}$ & $35.5 \%(11 / 31)$ & $62.5 \%(5 / 8)$ \\
\hline
\end{tabular}


considering the timing of appearance of antibody to SARSCoV-2 in serum to choose the best time for getting appropriate results. In this context, Zhao et al. disclosed the seroconversion rate for total antibody, IgM and IgG was $93.1 \%$, $82.7 \%$, and $64.7 \%$ in confirmed COVID-19, respectively. The median time for seropositivity of total antibody, IgM, and then IgG were days 11, 12, and 14, separately. They also reported the presence of antibodies only in $<40 \%$ of patients within 7 days since onset, while it increased rapidly to $100.0 \%$ (total antibody), $94.3 \%$ (IgM), and $79.8 \%$ (IgG) for 15 days after disease onset. Conversely, the detectability rate of SARS-CoV-2 RNA reduced from $66.7 \%$ (58/87) in samples obtained before day-7 to $45.5 \%$ (25/55) during day 15-39 [13]. Another study showed a rapid increase in the antibody level since 6 days post-exposure along with a decline of viral load [14]. The results obtained from a cohort serology study of COVID-19 patients exhibited that all patients achieved seroconversion of IgG within 17-19 days after symptom onset. Although the peak of IgM seroconversion rate was $94.1 \%$ at around 20-22 days after symptoms onset [13]. The application of serological test will be extended in recovered patients with preceding exposure to SARS-CoV-2. As our results pointed out that IgM and IgG were detected in $76.5 \%$, and $94.1 \%$, of COVID-19 recovered patients, respectively.

Thevarajan et al. reported a progressive increase in plasma SARS-CoV-2-binding IgM and IgG antibodies from day 7 until day 20 [15]. Increased level of specific antibody may be related to disease severity, immune pathogenesis, and therapeutic approaches in COVID-19 [13, 16, 17]. More recently it has been revealed that the positive rate of SARS-CoV-2 IgG reached $100 \%$ approximately 17-19 days after symptoms onset, whereas, IgM peak reached $94.1 \%$ at 20-22 days after disease symptoms onset. In addition, follow-up of 26 seronegative patients showed that all patients achieved seroconversion of both $\operatorname{IgG}$ and $\operatorname{IgM}$ within 20 days after symptom onset median day of 13 days post-symptom onset [13].

Moreover, studies demonstrated that serological tests can detect patients who have either current or previous infection with a negative PCR test. The duration time for detection of $\mathrm{N}$-specific antibody against SARS-CoV-2 including IgM, and $\operatorname{IgA}$ were 5 days, while for $\operatorname{IgG}$ were 14 days, with a positive rate of $85.4 \%, 92.7 \%$, and $77.9 \%$, respectively [18]. Indicating that serological tests, particularly in combined with RT-PCR can help COVID-19 diagnosis, even days after initial onset of symptoms. Our data highlighted that virus-specific antibody detection could be applicable as a complementary tool for nucleic acid assay in the diagnosis of COVID-19, especially in cases with negative RT-PCR. Thus, confirming suspected COVID-19 cases using serological testing could be useful to reduce false-negative results and improve invaluable RT-PCR tests. In compliance with our finding, Zhao et al. reported that combination of RNA and antibody detections markedly enhanced the sensitivity of diagnosis for COVID-19 [13]. Other study founded a rapid increased in the antibody level since 6 days postexposure along with a decline of viral load [14].

In the current study, combination of $\operatorname{IgM} / \mathrm{IgG}$ resulted in detection of $38.7 \%$, and $62.5 \%$ of RT-PCR negative cases in $\leq 7$ days, and $>7$ days intervals between sampling time and symptoms onset, respectively. Interestingly, combination of molecular and serological testing greatly improved the sensitivity of COVID-19 patient diagnosis. We exhibited the implication of PCR altogether with one of IgM or IgG results augmented the patient diagnosis sensitivity to $63.5 \%$ and $87.2 \%$ in $\leq 7$ days, and $>7$ days intervals, respectively. Our findings highlighted that the combination of CT scan and/or RT-PCR with serological testing can efficiently improve COVID-19 detection, even in the early stage of the disease. Mounting an antibody response in COVID-19 patients can be essential for determination of disease outcome as well as for patients to overcome a challenge from this pathogen. Taken together, these results demonstrated that serological tests, particularly in combined with RT-PCR can help to improve the sensitivity of COVID-19 diagnosis, even days after the initial onset of symptoms as well as in recovered patients.

Acknowledgements We would like especially thanks to Pishtaz Teb diagnostics for providing us with the SARS-CoV-2 ELISA kits.

Funding This work financially supported by Shahid Beheshti University of Medical Sciences (Grant number 23096). The funders had no role in study design, data collection and analysis, decision to publish, or preparation of the manuscript.

\section{Declarations}

Conflict of interest The author(s) declare no competing interests.

Ethics statement The authors are accountable for all aspects of the work in ensuring that questions related to the accuracy or integrity of any part of the work are appropriately investigated and resolved. Written informed consent was obtained from patients, as well as hospital authorities and institutional ethical committee prior to the study. This study was reviewed and approved by the Medical Ethical Committees of Shahid Beheshti University of Medical Sciences (approval number IR.SBMU.MSP.REC.1399.031).

Consent for publication All the authors of this study agreed to participate in this study. The corresponding author accepts responsibility for releasing this material on behalf of any and all co-authors.

\section{References}

1. Guan WJ, Ni ZY, Hu Y, Liang WH, Ou CQ, He JX, Liu L, Shan H, Lei CL, Hui DSC, Du B, Li LJ, Zeng G, Yuen KY, Chen RC, Tang CL, Wang T, Chen PY, Xiang J, Li SY, Wang JL, Liang ZJ, 
Peng YX, Wei L, Liu Y, Hu YH, Peng P, Wang JM, Liu JY, Chen Z, Li G, Zheng ZJ, Qiu SQ, Luo J, Ye CJ, Zhu SY, Zhong NS, China Medical Treatment Expert Group for C (2020) Clinical characteristics of coronavirus disease 2019 in China. N Engl J Med 382(18):1708-1720. https://doi.org/10.1056/NEJMoa2002 032

2. Hui DS, Azhar EI, Madani TA, Ntoumi F, Kock R, Dar O, Ippolito G, Mchugh TD, Memish ZA, Drosten C (2020) The continuing 2019-nCoV epidemic threat of novel coronaviruses to global health - the latest 2019 novel coronavirus outbreak in Wuhan, China. Int J Infect Dis 91:264-266. https://doi.org/10.1016/j.ijid. 2020.01.009

3. Guo YR, Cao QD, Hong ZS, Tan YY, Chen SD, Jin HJ, Tan KS, Wang DY, Yan Y (2020) The origin, transmission and clinical therapies on coronavirus disease 2019 (COVID-19) outbreakan update on the status. Mil Med Res 7(1):11. https://doi.org/10. 1186/s40779-020-00240-0

4. Chen N, Zhou M, Dong X, Qu J, Gong F, Han Y, Qiu Y, Wang J, Liu Y, Wei Y, Xia J, Yu T, Zhang X, Zhang L (2020) Epidemiological and clinical characteristics of 99 cases of 2019 novel coronavirus pneumonia in Wuhan, China: a descriptive study. Lancet 395(10223):507-513. https://doi.org/10.1016/S0140-6736(20) 30211-7

5. Lai CC, Shih TP, Ko WC, Tang HJ, Hsueh PR (2020) Severe acute respiratory syndrome coronavirus 2 (SARS-CoV-2) and coronavirus disease-2019 (COVID-19): The epidemic and the challenges. Int J Antimicrob Agents 55(3):105924. https://doi.org/10.1016/j. ijantimicag.2020.105924

6. Huang C, Wang Y, Li X, Ren L, Zhao J, Hu Y, Zhang L, Fan G, Xu J, Gu X, Cheng Z, Yu T, Xia J, Wei Y, Wu W, Xie X, Yin W, Li H, Liu M, Xiao Y, Gao H, Guo L, Xie J, Wang G, Jiang R, Gao Z, Jin Q, Wang J, Cao B (2020) Clinical features of patients infected with 2019 novel coronavirus in Wuhan, China. Lancet 395(10223):497-506. https://doi.org/10.1016/S0140-6736(20) 30183-5

7. Jin YH, Cai L, Cheng ZS, Cheng H, Deng T, Fan YP, Fang C, Huang D, Huang LQ, Huang Q, Han Y, Hu B, Hu F, Li BH, Li YR, Liang K, Lin LK, Luo LS, Ma J, Ma LL, Peng ZY, Pan YB, Pan ZY, Ren XQ, Sun HM, Wang Y, Wang YY, Weng H, Wei CJ, Wu DF, Xia J, Xiong Y, Xu HB, Yao XM, Yuan YF, Ye TS, Zhang XC, Zhang YW, Zhang YG, Zhang HM, Zhao Y, Zhao MJ, Zi H, Zeng XT, Wang YY, Wang XH, Management ftZHoWUNC, Research Team E-BMCoCIE, Promotive Association for M, Health C (2020) A rapid advice guideline for the diagnosis and treatment of 2019 novel coronavirus (2019-nCoV) infected pneumonia (standard version). Mil Med Res 7(1):4. https://doi.org/10. 1186/s40779-020-0233-6

8. Liu S, Luo H, Wang Y, Cuevas LE, Wang D, Ju S, Yang Y (2020) Clinical characteristics and risk factors of patients with severe COVID-19 in Jiangsu province, China: a retrospective multicentre cohort study. BMC Infect Dis 20(1):1-9. https://doi.org/10.1186/ s12879-020-05314-x

9. Bai Y, Yao L, Wei T, Tian F, Jin DY, Chen L, Wang M (2020) Presumed asymptomatic carrier transmission of COVID-19. JAMA 323(14):1406-1407. https://doi.org/10.1001/jama.2020.2565
10. Xie X, Zhong Z, Zhao W, Zheng C, Wang F, Liu J (2020) Chest CT for typical coronavirus disease 2019 (COVID-19) pneumonia: relationship to negative RT-PCR testing. Radiology 296(2):E41E45. https://doi.org/10.1148/radiol.2020200343

11. Yang Y, Yang M, Shen C, Wang F, Yuan J, Li J, Zhang M, Wang Z, Xing L, Wei J (2020) Laboratory diagnosis and monitoring the viral shedding of 2019-nCoV infections. MedRxiv. https://doi.org/ 10.1101/2020.02.11.20021493

12. Rothe C, Schunk M, Sothmann P, Bretzel G, Froeschl G, Wallrauch C, Zimmer T, Thiel V, Janke C, Guggemos W, Seilmaier M, Drosten C, Vollmar P, Zwirglmaier K, Zange S, Wolfel R, Hoelscher M (2020) Transmission of 2019-nCoV infection from an asymptomatic contact in germany. N Engl J Med 382(10):970971. https://doi.org/10.1056/NEJMc2001468

13. Zhao J, Yuan Q, Wang H, Liu W, Liao X, Su Y, Wang X, Yuan J, Li T, Li J, Qian S, Hong C, Wang F, Liu Y, Wang Z, He Q, Li Z, He B, Zhang T, Fu Y, Ge S, Liu L, Zhang J, Xia N, Zhang Z (2020) Antibody responses to SARS-CoV-2 in patients with novel coronavirus disease 2019. Clin Infect Dis 71(16):2027-2034. https://doi.org/10.1093/cid/ciaa344

14. Lou B, Li TD, Zheng SF, Su YY, Li ZY, Liu W, Yu F, Ge SX, Zou QD, Yuan Q, Lin S, Hong CM, Yao XY, Zhang XJ, Wu DH, Zhou GL, Hou WH, Li TT, Zhang YL, Zhang SY, Fan J, Zhang J, Xia NS, Chen Y (2020) Serology characteristics of SARS-CoV-2 infection after exposure and post-symptom onset. Eur Respir J 56:2. https://doi.org/10.1183/13993003.00763-2020

15. Thevarajan I, Nguyen THO, Koutsakos M, Druce J, Caly L, van de Sandt CE, Jia X, Nicholson S, Catton M, Cowie B, Tong SYC, Lewin SR, Kedzierska K (2020) Breadth of concomitant immune responses prior to patient recovery: a case report of non-severe COVID-19. Nat Med 26(4):453-455. https://doi.org/10.1038/ s41591-020-0819-2

16. Jiang S, Hillyer C, Du L (2020) Neutralizing antibodies against SARS-CoV-2 and other human coronaviruses. Trends Immunol 41(5):355-359. https://doi.org/10.1016/j.it.2020.03.007

17. Huang AT, Garcia-Carreras B, Hitchings MDT, Yang B, Katzelnick LC, Rattigan SM, Borgert BA, Moreno CA, Solomon BD, Rodriguez-Barraquer I, Lessler J, Salje H, Burke D, Wesolowski A, Cummings DAT (2020) A systematic review of antibody mediated immunity to coronaviruses: antibody kinetics, correlates of protection, and association of antibody responses with severity of disease. medRxiv. https://doi.org/10.1101/2020.04.14.20065771

18. Guo L, Ren L, Yang S, Xiao M, Chang YF, Dela Cruz CS, Wang Y, Wu C, Xiao Y, Zhang L, Han L, Dang S, Xu Y, Yang QW, Xu SY, Zhu HD, Xu YC, Jin Q, Sharma L, Wang L, Wang J (2020) Profiling early humoral response to diagnose novel coronavirus disease (COVID-19). Clin Infect Dis 71(15):778-785. https://doi. org/10.1093/cid/ciaa310

Publisher's Note Springer Nature remains neutral with regard to jurisdictional claims in published maps and institutional affiliations. 